\title{
Licenciatura em Educação do Campo: intencionalidades na formaçáo de educadores do campo no Marajó
}

\author{
ELIANE MIRANDA COSTA \\ Secretaria de Estado de Educação - SEDUC-PA, Brasil \\ Recibido el 14-11-2015; primera evaluación el 11-05-2016; segunda \\ evaluación el 20-10-2016; aceptado el 27-10-2016
}

\section{RESUMO}

O texto resulta da pesquisa de mestrado realizada no município de Portel, no arquipélago do Marajó. Objetiva discutir as intencionalidades da formação de educadores do campo a partir do curso de Licenciatura em Educação do Campo. Metodologicamente trata-se de um estudo de caso do tipo único de abordagem qualitativa, que coletou os dados por meio das seguintes técnicas: entrevista semiestruturada, observação não-participante, questionário fechado e análise documental. Os dados analisados à luz da técnica da análise de conteúdo em diálogo com teóricos, a exemplo de Arroyo (2011), Caldart (2010), Molina (2011) e outros, possibilitaram considerar que uma das intençóes da formação é a conquista de novas escolas, náo no sentido de uma nova estrutura física, mas de um espaço aberto ao diálogo e ao debate.

Palavras-chave: educação do campo, formação de educadores, intencionalidades.

\footnotetext{
Licenciada Plena em Pedagogia, pela Universidade Federal do Pará (UFPA), Campus Universitário do Marajó-Breves (2005). Possui Especialização em Educação do Campo, Desenvolvimento e Sustentabilidade, pela UFPA (2010). É mestre em Educação (2012), Linha de Pesquisa Formação de Professores, pela Universidade do Estado do Pará (UEPA), com período Sanduíche no Programa de Pós-graduaçáo da Pontifícia Universidade Católica do Rio Grande do Sul (PUCRS) por meio do Programa Nacional de Cooperação Acadêmica (PROCAD). Doutoranda do curso de Antropologia - área de concentração arqueologia - do PPGA da UFPA. Participa do Programa Nacional de Formação dos Professores da Educação Básica (Parfor) na condição de professor formador. É técnica em educaçáo da Secretaria de Estado de Educação do Pará (SEDUC-PA). Contacto: elyany2007@hotmail.com
} 
Degree in Rural Education: Intentions in the Training of Field Educators in Marajó

\section{Abstract}

The text is the result of the master survey conducted in the city of Portel, in the archipelago of Marajó. It ims to discuss the intentions of forming educators of the field from the Bachelor's Degree in Rural Education. Methodologically it is a case study of one type of qualitative approach, which collected the data using the following techniques: semi-structured interviews, non-participant observation, closed questionnaire and document analysis. The data analyzed in the light of the content analysis technique in dialogue with theorists, like Arroyo (2011), Caldart (2010), Molina (2010) and others, made it possible to consider that one of the forming intentions is the conquest of new schools not in the sense of a new physical structure, but an open space for dialogue and debate.

Keywords: rural education, teacher training, intentions.

Licenciatura en Educación Rural: las intenciones en la formación de educadores de campo en Marajó

\section{Resumen}

El texto es el resultado de la encuesta de la muestra realizada en la ciudad de Portel, del archipiélago Marajó. Tiene como objetivo discutir las intenciones de la formación de educadores del campo de la Licenciatura en Educación Rural. Metodológicamente se trata de un estudio de caso de un tipo de enfoque cualitativo, que recoge los datos mediante las siguientes técnicas: entrevistas semiestructuradas, observación no participante, cuestionario cerrado y análisis de documentos. Los datos analizados a la luz de la técnica de análisis de contenido en el diálogo con los teóricos, como Arroyo (2011), Caldart (2010), Molina (2010) y otros, hicieron posible considerar que una de las intenciones de formación es la conquista de nuevas escuelas no en el sentido de una nueva estructura física, sino un espacio abierto para el diálogo y el debate.

Palabras clave: educación rural, formación del profesorado, intenciones. 


\section{INTRODUÇÃo}

O texto analisa as intencionalidades da formação de educadores do campo a partir do curso de Licenciatura Plena em Educação Campo (LPEC) desenvolvido em Portel, município paraense no arquipélago do Marajó. É um estudo que resulta minha pesquisa de mestrado no âmbito do Programa de Pós-graduação em Educação da Universidade do Estado do Pará. Nesta pesquisa tenho como objeto o Programa de Apoio à Formação Superior em Licenciatura em Educação do Campo (Procampo). Em sua realização adotei como estratégia metodológica o estudo de caso, com as seguintes técnicas de coleta de dados: entrevista semiestruturada, observação não-participante, questionário fechado e análise documental. Os dados foram analisados com base em aspectos da técnica da análise de conteúdo.

Neste estudo foram entrevistados 04 formadores (PF) do curso, 06 formandos (EF) e 02 coordenadoras pedagógicas (CP). O questionário fechado foi aplicado junto a 40 alunos da turma de LPEC em Portel. Este instrumento foi organizado com 10 (dez) perguntas referentes à formação, o tempo de atuação na docência no campo e às condiçóes de trabalho na escola do campo com a finalidade de caracterizar a referida turma. Já a observação envolveu a seguinte sistemática: durante 20 dias de segunda a sábado, no período da manhã e da tarde, conforme aconteciam às aulas foram acompanhadas as atividades pedagógicas, orientada por um roteiro que ajudou a registrar no caderno de campo os dados observados. Para efeito deste texto, as análises e reflexôes apresentadas resultam dos dados coletados com a entrevista, observação e análise de documentos.

Assim, para discorrer sobre as intencionalidades da formação na LPEC, este texto discute, a priori, a dinâmica de criaçáo do Procampo, em 2006 pelo MEC, em que destaca ser esta uma política aprovada com a finalidade de apoiar a implementação de cursos regulares de LPEC em Instituições Públicas de Ensino Superior (IPES) no país. Na sequência, evidencia-se o processo formativo empreendido na licenciatura em Portel, com ênfase nos elementos estruturantes da formação, isto é, docência multidisciplinar, área de conhecimento e alternância pedagógica. Nas considerações refutam-se reflexôes que se constituem importantes para futuras pesquisas. 


\section{Procampo: as intençóes de uma política na formaÇáo do eduCador DO CAMPO}

O Procampo resulta da luta histórica da educação do campo que envolveu um intenso processo de mobilização e reivindicação protagonizado pelos movimentos sociais e sindicais do campo, com destaque para o Movimento dos Trabalhadores Rurais Sem Terra, que em parceira com as universidades públicas, intelectuais e ONG»s conseguiu inserir na pauta da agenda governamental à proposição de uma política nacional de formação docente específica e permanente, voltada para valorizar os sujeitos do campo e suas formas de organização de vida e trabalho.

Em resposta, a tal demanda o MEC convidou um grupo de especialistas ligados às universidades e aos movimentos sociais para elaborarem e apresentarem uma proposta concreta de formação de educadores/as do campo (Santos, 2009). Essa Comissão sistematizou a proposiçáo do curso de LPEC, em que definiu diretrizes, princípios, metodologia, sujeitos atendidos, forma de implementação e instituiçôes responsáveis pela execução (Henriques, Marangon, Delamora \& Chamusca, 2007).

Caldart membro da referida comissão relata na dissertação de Santos (2009), que a criação do curso de LPEC envolveu uma sistemática complexa e desafiadora, balizada por um intenso debate acerca dos impasses que surgiram no decorrer do processo de construção dessa licenciatura, sobretudo em relação à legalidade, isso porque «o formato legal e institucional das licenciaturas existentes no sistema educacional é expressão de uma concepção de formação de educadores e de escola que diverge dos debates originários da Educação do Campo" (Caldart, 2011, p. 100). Em meio ao impasse da legalidade, o desafio foi criar estratégias para seguir um caminho que possibilitasse construir uma proposta de política de formação de educadores exequível, concreta, que não se reduzisse em apenas um documento.

Nesse movimento, primou-se pelo resgate da experiência do Programa Nacional de Reforma Agrária (Pronera), com os cursos de Pedagogia da Terra em parcerias com universidades públicas. Especial atençáo deu-se ao curso da Universidade Federal de Minas Gerais (UFMG), em desenvolvimento, na época, devido este voltar-se para formar o educador para atuar nos anos iniciais e finais do ensino fundamental e no ensino médio, aliados ao processo de gestão, pesquisa e intervenção na educação do campo.

Em geral, a construção da proposta do curso de LPEC provocou o debate sobre o perfil do profissional a ser formado, a realidade escolar que este profissional iria atuar, a forma deste se organizar, bem como as competências 
necessárias para atuar nas escolas do campo. Além disso, também, se refletiu acerca do projeto pedagógico para referenciar essa formação, o amparo legal, dentre outros aspectos concernentes ao contexto do campo. $\mathrm{O}$ objetivo foi construir uma proposta de formaçáo «que respondesse às necessidades de fortalecimento e ampliação da oferta da Educação Básica no campo» (AntunesRocha, 2009, p. 41).

Nesse processo, surgiu o desafio de superar o modelo disciplinar do currículo, e colocar em prática uma formação multidisciplinar por área de conhecimento em regime de alternância pedagógica, entendendo que,

[...] a formaçáo por área poderia ser um caminho para garantir o funcionamento de salas de segundo segmento do ensino fundamental e ensino médio no campo, constituindo-se assim como alternativa em um cenário em que a nucleação e o transporte dos alunos para escolas distante de suas residências têm sido as únicas possibilidades para a escolarização da educação do campo (Antunes-Rocha, 2009, p. 41).

Daí entender que a formação por área é uma opção encontrada pelo Movimento de Educaçáo do Campo para por em prática a formaçáo do docente do campo. Não se pode esquecer que a área é opção do próprio Estado/ Governo para promover a formaçấo docente de modo geral, a partir da aprovação das Diretrizes Curriculares Nacionais para a Formação de Professores da Educação Básica, em nível superior, curso de licenciatura, de graduação plena (2002) a qual dá subsídio a LPEC.

A proposição, então, se encaminhou para uma organizaçáo curricular voltado para a docência multidisciplinar por área de conhecimento, incluindo as quatro áreas: Ciências Naturais e Matemática; Ciências Humanas e Sociais; Linguagens, Artes e Literatura e Ciências Agrárias, com a possibilidade de habilitar o docente em uma dessas áreas. Com isso, tem-se o docente habilitado em uma área e não o docente de disciplinas, ou seja, o especialista em matemática, física, química, biologia, história, entre outras, como ocorre nas demais licenciaturas.

A organização por área, também, se justifica por se entender que seria inviável garantir escolas de Educação Básica completa nas comunidades do campo nos moldes das licenciaturas disciplinares, devido à «inviabilidade de manter um professor por disciplina em escolas que nem sempre conseguem ter um número grande de estudantes e cuja localizaçáo torna mais difícil à lógica de cada professor trabalhar em diversas escolas para completar sua carga horária» (Caldart, 2011, p. 106). 
Como a ideia de área já estava nas Diretrizes do próprio MEC poderia ser uma forma mais facilmente aceita. Com isso, a formação por área poderia ser trabalhada na perspectiva de viabilizar a criação de mais escolas no campo, bem como fortalecer a proposta de um trabalho integrado no sentido de superar a lógica fragmentada do currículo. Para tanto, conforme indica Caldart (2011) a área precisa ancorar-se em uma análise histórico-crítica da escola, isto é, da tarefa educativa da escola do campo em vista de compreender a necessidade de sua transformação mais radical. Em outros termos significa dizer, uma formação por área que possibilite romper com uma possibilidade de área ancorada na visão neoliberal de escola, em que prevalece uma pedagogia voltada para uma pseudo desfragmentaçáo do conhecimento.

Ao se entender que a realidade do campo exige um profissional com formação mais ampliada, a demanda de uma formação multidisciplinar exigiu o repensar dos conteúdos, bem como do tempo, espaço, propostas metodológicas, em que se decidiu pela opção da organização em regime de alternância pedagógica entre Tempo Escola (TE) e Tempo Comunidade (TC) tendo por base a experiência dos cursos do Pronera. A opção pela Pedagogia da Alternância justifica-se por esta configurar-se como um método, uma alternativa metodológica que alterna situações de aprendizagem escolar com situaçóes de trabalho produtivo, que tem por elementos orientadores a experiência do aluno, o contexto em que está inserido, bem como as marcas identitárias da população do campo (Ribeiro, 2010).

Esses tempos/espaços (TA e TC) são definidos por Cordeiro (2009, p. 63) como, "práticas criadas na luta pela terra e pela escola». A autora ajuda entendê-los como espaços/tempos conquistados para garantir a integração e articulaçáo do saber empírico com o conhecimento científico. Para isso, a proposta adotou como princípios formativos a interdisciplinaridade e a transdisciplinaridade.

Caldart (2011, p. 108) explica que esses princípios «foram colocadas como objetivos da formação, por se entender que indicavam muito mais perspectivas de trabalho docente do que a forma de uma habilitação específica». Identifica-se que esses princípios podem contribuir para superar no curso a fragmentaçáo do conhecimento.

No geral, propôs-se um curso que promovesse a formação específica por entender que isso representa «ir além da reivindicação de acesso, inclusão e pertencimento» (Brasil, 2001, p. 12). Essa é uma questão, segundo Arruda e Brito (2009) que precisa ser analisada em profundidade, pois a defesa pelo específico é permeada por várias perspectivas. Reafirmam que as singularidades expostas por meio do discurso da especificidade do modo de viver no 
campo são criação do próprio capital e, que, portanto, não é exclusividade do campo. Afirmam que a defesa do específico fora do quadro de suas relaçóes com a totalidade obscurece mais ainda a visão de mundo dos sujeitos.

Para Caldart (2011, p. 155) a "especificidade se refere fundamentalmente aos processos produtivos e de trabalho no campo das lutas sociais e da cultura produzida deste processo de reproduçáo da vida, de luta pela vida». O foco na especificidade não se trata de negar o universal, nem absolutizar o particular, mas possibilitar «que o particular entre no universal e assim sendo, o universal torne-se mais universal» (Caldart, 2011, p. 70).

Essa autora contribui para se entender que a formação específica visa contribuir com a expansão da Educação Básica nas escolas do campo no intuito de superar as desvantagens educacionais vividas historicamente pelos sujeitos do campo e indica que a política educacional ganha uma nova estrutura. Isso porque, o campo antes visto apenas como celeiro de matéria-prima, agora é espaço de vida e história a ser valorizado. Isso não significa dizer que o campo deixou de ser visto como produtor primário, esse ideário ainda permanece, sobretudo, com o agronegócio. Porém, a mudança nessa lógica é que os sujeitos do campo, produtores de matéria-prima, passam a serem vistos como produtores de vida e história.

Nessa sistemática, nasceu o curso de LPEC, fundamentado de maneira legal na LDB (n.9.394/1996); Parecer CNE/CEB 36/2001 e Resolução CNE/ CEB 1/2001 que institui as Diretrizes Operacionais para a Educação Básica nas Escolas do Campo (DOEBEC); Parecer CNE/CEB 09/2001 e Resolução CNE/CEB 1/2002 que institui as Diretrizes Curriculares Nacionais para a Formação de Professores da Educação Básica, em nível superior curso de licenciatura de graduação plena.

$\mathrm{Na}$ perspectiva de implantação imediata da licenciatura via Procampo, o MEC convocou por meio de carta-convite, em 2007, às universidades públicas que já acumulavam experiência com a formação de educadores do campo para implantar o Projeto Piloto do curso de LPEC. Para tanto, foram convidadas sete $\left(07^{1}\right)$ universidades federais. Desse total, 04 (UnB, UFMG, UFS e UFBA) começaram a desenvolver o referido curso neste mesmo ano.

A partir da experiência desses projetos-pilotos, o Ministério da Educação (MEC) lançou, em 2008 o Edital no02/2008 convocando às IPES a apresentarem projetos de criação da nova licenciatura. $\mathrm{Na}$ mesma expectativa este

1 Universidade Nacional do Brasil, Universidade Federal da Bahia, Universidade Federal do Pará, Universidade Federal de Campina Grande, Universidade Federal de Minas Gerais, Universidade Federal de Sergipe, Universidade Tecnológica Federal do Paraná. 
Ministério lançou em 2009 o Edital n09/2009. Nesses editais, acentua-se como objetivo do Procampo, apoiar e fomentar «projetos de cursos de licenciatura específicos em educação do campo que integrem ensino, pesquisa e extensão e promovam a valorizaçâo da educação do campo e o estudo dos temas relevantes concernentes às suas populações» (Brasil, 2008, p. 1, grifo nosso).

Recomendam ainda que «os projetos apoiados deverão contemplar alternativas de organização escolar e pedagógica» que venha contribuir com «a expansão da oferta da educaçáo básica nas comunidades rurais e para a superação das desvantagens educacionais históricas sofridas pelas populaçôes do campo» (Brasil, 2008, p. 1). Com a emissão desses editais o MEC torna público, em âmbito nacional, à institucionalizaçáo do Procampo e inaugura assim uma política específica de formação para os/as educadores/as do campo. A dinâmica dessa formação será evidenciada, no tópico a seguir.

\section{A LPEC E O PROCESSO FORMATIVO: REFLEXÓES SOBRE OS OBJETIVOS DA FORMAÇÁO E A ATUAÇÃO DOCENTE}

$\mathrm{O}$ exposto anteriormente indica que o processo formativo compreende a docência multidisciplinar por área de conhecimento em regime de alternância pedagógica. $\mathrm{O}$ que contribui para a existência de um profissional no campo habilitado para realizar um trabalho que na maioria ele faz sem à devida formaçáo. O depoimento abaixo esclarece ser a formaçáo por área uma importante ferramenta para fortalecer a educação do campo na região marajoara, uma vez que se configura como possibilidade de integraçáo e construçáo de saberes. Vejamos:

Para a educação do campo a formação por área é fundamental [...] fortalecer a área do conhecimento, é olhar um determinado objeto a partir de várias possibilidades, por exemplo, é olhar o ser humano na relação com a escola através da geografia, da história, da sociologia, da filosofia e a partir de aí construir outros conhecimentos dialogando esses saberes (CP01).

O depoimento possibilita entender e reafirmar que a formação por área é uma importante estratégia para a política de expansão da educação básica no campo, bem como para a transformaçáo da escola. Todavia depende da materialidade dessa licenciatura que vai além da formação por área. E um importante elemento nesse processo é o próprio currículo.

Na perspectiva de Arroyo (2011, p. 13) o currículo é o «núcleo e o espaço central mais estruturante da função da escola» e que, em geral, tem ocultado o saber dos alunos e professores. Por isso, defende que seja (re) politizado, que 
integre os saberes, vivências dos/as educadores/as e dos/as educandos/as no sentido de contribuir para que a escola e a sociedade os reconheçam e valorizem como sujeitos histórico-sociais. E, que os próprios sujeitos se percebam e se reconheçam como sujeitos de conhecimento.

No particular desta licenciatura em Portel a formação por área pauta-se pelo desenvolvimento do currículo nos tempo/espaço educativos, contemplando o trabalho pedagógico em uma perspectiva interdisciplinar com base em uma metodologia de integração das disciplinas (IFPA, 2011). Diante disso, coloca dois professores juntos no mesmo espaço/tempo para ministrarem duas disciplinas, em que cada professor é responsável por uma disciplina.

Com as observaçóes empreendidas no $3^{\circ}$ TA constatamos que o trabalho pedagógico interdisciplinar pouco ocorreu, uma vez que na maioria do tempo os professores dividiram os horários para que cada um ministrasse a sua disciplina, e os poucos momentos que compartilharam espaço e tempo, a integração das disciplinas pouco se efetivou. Assim, podemos afirmar que a maioria dos formadores reforçou o caráter disciplinar e compartimentado do conhecimento, o que pode ser exemplificado quando um desses formadores solicita aos educandos para "fecharem em suas cabeças a gaveta das outras áreas de conhecimento e abrirem apenas uma gaveta específica» (PF). Além disso, tem-se a redução da carga horária de $42 \mathrm{~h}$ de cada disciplina para $24 \mathrm{~h}$ à $28 \mathrm{~h}$, com raras exceçôes.

É válido destacar nesse processo a realização da atividade de visita/pesquisa de campo no final das disciplinas como um dos principais momentos que observamos esforço por parte de alguns formadores e formandos para integrar as referidas disciplinas. Porém, em sala de aula, no geral observamos pouca tentativa nesse sentido. Cabe dizer que, a maioria dos debates e reflexóes realizadas em sala ficou restrita aos conteúdos dos livros-textos, ou melhor, dizendo a abstraçóes teóricas concernentes a cada disciplina.

Tomando por base os escritos de Fazenda (2008) entende-se que desenvolver um currículo e um trabalho pedagógico interdisciplinar não é uma tarefa fácil e simples de fazer ao considerar a histórica formação do educador brasileiro, como expressa um dos entrevistados:

A formação do professor deve ser interdisciplinar, multidisciplinar, integrada, mas não é fácil realizar uma formaçáo multidisciplinar, quando a formação do professor que forma é disciplinar. [...] dentro da proposta da educação do campo, há áreas de conhecimentos que são extremamente possíveis de afinidade, portanto, o trabalho integrado pode ser produtivo, mas, devido nossa formação disciplinar, fechada, recortada, há outras áreas muito difíceis de parceria [...]. (PF01). 
Realizar um trabalho interdisciplinar quando a formação de quem forma é disciplinar impóe limites e torna o processo muito mais difícil, uma vez que um trabalho educativo interdisciplinar não consiste em apenas estabelecer o diálogo entre as disciplinas, mas possibilitar a integração da teoria e prática como unidade dialética, e isso exige conhecer aspectos históricos do contexto. Daí a necessidade de estratégias metodológicas conectadas com as realidades presentes no campo.

Tem-se ainda o fato de tratar-se de um trabalho que coloca o professor em uma situaçáo teoricamente desconfortável, devido este ter que dividir seu campo/área de domínio e, ao mesmo tempo, transitar, por outros campos/ áreas e isso exige competência teórico-prática para fazê-la. Nesse processo o educador precisa se envolver, dispor-se e apostar na interdisciplinaridade. É preciso ainda que a universidade se transforme «em um amplo laboratório de conhecimento/pensamento" (Jantsch \& Bianchetti, 2011, p. 180) no sentido de «criar e aprofundar espaços de iniciaçáo científica e de pesquisas avançadas» (Jantsch \& Bianchetti, 2011, p. 180).

Considera-se esse, um desafio tanto para os formadores como para os próprios formandos no constituir dessa licenciatura. Materializar um currículo e um trabalho pedagógico interdisciplinar está diretamente relacionado à formação do formador. Uma formação que como disposto corresponde ao modelo disciplinar consolidado no âmbito acadêmico, com foco na especialidade e no conhecimento compartimentado. Superar essa tradição histórica não é algo que ocorrerá de imediato, é um trabalho longo, difícil que «exige uma mudança da vida acadêmico-universitária» (Jantsch \& Bianchetti, 2011, p. 180), além do empenho e do próprio querer dos formadores.

A interdisciplinaridade propóe-se superar o processo de especialização do saber, transposto para o currículo como disciplinas, e busca integrar os diversos saberes em vista de construir e materializar o chamado currículo interdisciplinar. Esse entendimento corrobora para a importância de uma proposta pedagógica plural, múltipla que evidencie a diversidade da Amazônia paraense. Contudo, sabe-se que uma proposta assim náo é nada fácil de materializar, considerando a complexidade das peculiaridades de cada canto da Amazônia paraense e marajoara, o que significa enfatizar que uma proposta, por mais dinâmica, plural que seja não dá conta de abarcar toda essa diversidade, apesar de ser apenas uma referência.

Ao valer dos escritos de Kuenzer (2011, p. 678), entende-se que,

[...] a proposta pedagógica tem papel fundamental a desempenhar na formação e profissionalização de professores que, por sua vez, vão formar homens e 
mulheres através de propostas curriculares. A qualidade da formação, contudo, vai depender das concepçôes ontológicas e epistemológicas que sustentam essas propostas curriculares, a partir das quais se formulam diferentes concepçóes de homem, de trabalho e de sociedade.

Materializar uma proposta que abarque as marcas identitárias dos sujeitos do campo não depende apenas do que está exposto em um documento, ou da existência de várias propostas, mas, sobretudo, das condiçôes oferecidas aos formandos e formadores, bem como do fazer pedagógico desses últimos. Entende-se a partir disso que defender um trabalho por área na perspectiva interdisciplinar é também propor-se a superar a divisão de horários, a fragmentaçáo do conhecimento nos tempos/espaços educativos, a forma de acompanhamento do TC. Isso implica (re) pensar a organização das disciplinas, e suas respectivas cargas horárias, assim como o longo período de TC e o apertado período de TA.

Nesse processo, a alternância pedagógica configura-se como um importante elemento da formação, como indicam os depoimentos abaixo:

A alternância pedagógica sustenta nossa metodologia enquanto licenciatura, náo dá para imaginar uma formaçáo de área sem um diálogo com que se estuda no TA e com que se vive na experiência [...] A experiência é base fundamental para a construção desse conhecimento. Garantir essa alternância pedagógica é garantir que a educaçáo do campo se construa como algo que seja marcado por um conhecimento, o científico, e não imaginar que é um saber deslocado, sem sentido, pelo contrário é um saber localizado, objetivado, organizado (CP01).

A Pedagogia da Alternância é fundamental para a regiáo amazônica e para a educação do campo. Com ela avançamos no que diz respeito à construção de uma política educacional sensível e comprometida com outras temporalidades e racionalidades, outras histórias, formas de organização social que se tem no Brasil, e no caso específico da Amazônia. O tempo do aluno na sala de aula e o tempo na comunidade, na vivência, nas atividades cotidianas, na construção de práticas de trabalho ou nas experiências de trabalho que desenvolvem para o sustento da família, deve ser levado em conta pelo sistema educacional. Este precisa articular vida, ensino, trabalho e estudo a realidade local e global (PF01).

Os depoimentos permitem evidenciar que a pedagogia da alternância é condição fundamental para a valorização da educação do e no campo da Amazônia Marajoara. Com essa pedagogia, a experiência do educando é considerada base da produção do conhecimento, pois, o trabalho é tido como princípio educativo. Isso indica que a prática é o ponto de partida e de chegada desse processo e a teoria o elemento referenciador, o que demonstra ser teoria e prática unidades dialéticas e não dicotômicas. 
Observamos que essa pedagogia reconhece o homem do campo a partir de sua temporalidade e racionalidade que difere do tempo e racionalidade de referência urbana. Daí entendê-la como forma de ruptura com o modelo de escola e educação presente no campo, porém, é uma pedagogia que precisa, como alerta um dos entrevistados, ser levada em conta pelo sistema educacional brasileiro, não só no sentido de reconhecer por meio de leis, mas de possibilitar que sua proposta se materialize.

$\mathrm{Na}$ disposição dessa licenciatura os pressupostos metodológicos da alternância como já citados são os itinerários formativos TA e TC. Esses «configuram-se como princípios e diretriz da organização dos processos formativos» da LPEC (Antunes-Rocha \& Martins, 2012, p. 22). No TA contempla-se atividade do espaço escolar, onde os educandos têm acesso ao conhecimento científico, por meio de livros, textos e diálogo com o professor formador. No $\mathrm{TC}$ os educandos realizam uma pesquisa junto à comunidade, que culmina no portfólio, um instrumento conforme Molina (2011, p. 53) «que registra e reflete a trajetória de saberes construídos». Isso possibilita «ao estudante uma compreensão mais ampla do processo ensino/aprendizagem» (Molina, 2011, p. 53). Tal entendimento é compartilhado pelos entrevistados:

O TE nos norteia para que possamos chegar às comunidades e aplicar aquilo que é repassado, nos dá embasamento teórico, nos norteia para que nós possamos realizar um trabalho bom no campo. E o TC nos possibilita conhecer a fundo a realidade que vivemos porque muitas vezes o professor ignora os fatos que acontecem na comunidade, às vezes, chega e sai da comunidade e náo procura conhecer as manifestaçóes culturais (EF02).

No TA temos o contato com as disciplinas voltadas para o campo, com a teoria. No TC trocamos informaçôes, conhecimentos, com a comunidade (EF06).

Esses depoimentos permitem esclarecer que o TA é o tempo em que se socializa a teoria com os formandos e o TC o momento que esses sujeitos tem para dialogar com a realidade, tendo por base a teoria apreendida no TA. Nessa perspectiva compreendemos o TA como o momento do debate e reflexão teórica articulada com a realidade, com a prática, a qual terá uma ênfase maior no TC, quando a teoria refletida permita ao educando dialogar com o contexto, de modo a (re) produzir conhecimentos e não simplesmente aplicá-los. E o TC é o itinerário formativo propício para potencializar não só a dimensão cognitiva, mas, afetiva, social, cultural, ambiental, étnica, entre outras. Temos assim, dois territórios distintos, mas não separados, que apresentam conflitos e consensos na construção da formação do educador do 
campo. Territórios que nos ajudam a provar que a formação docente está no e para além do espaço acadêmico.

Isso envolve um trabalho de ruptura com o paradigma dominante no ensino e na pesquisa, cuja realidade é a centralidade na articulação e debate do conhecimento científico com outros tipos de saberes, de modo que a realidade não seja apenas entendida, explicada, mas, também, transformada. Observamos que esse esforço vem sendo feito por alguns formadores e educandos. Mas, a prevalência ainda é do ensino compartimentado, tendo-se de um lado a teoria e de outro a prática. Inferimos com base nisso que romper com esse processo não é um exercício que se faça sem correr riscos, dada à novidade desta formação.

É no trabalho educativo realizado em conjunto que formadores e formandos darão materialidade a docência por área em regime de alternância, logo, a formação inicial dos/as educadores/as do campo como proposto no projeto desta licenciatura, que como indica tanto o Movimento de Educação do Campo quanto à própria política que a respalda, tem por objetivo conquistar escolas. E esse propósito vai além da construção do prédio pretende-se contribuir com a superação de um modelo educativo que na maioria serve para excluir os sujeitos do campo. Daí a defesa de uma proposta curricular plural que contribua para construir uma nova escola no e do campo na Amazônia paraense e marajoara. Uma escola humana para formar o cidadáo do campo.

Para tanto, carece formar professores responsáveis, sensíveis, comprometido, atuante, articulador do conhecimento, como revela o seguinte depoimento:

Precisa ser um professor articulador do saber, articulador do conhecimento teórico com o conhecimento empírico. Este profissional deve provocar discussáo dessa relação do conhecimento dentro da sala de aula, e buscando também envolver a comunidade, as pessoas que estão em volta da escola, porque esse é o papel social da escola (PF02).

Essa voz corrobora para o que Monteiro e Nunes (2010, p. 264) advertem quando tratam da profissão docente no atual contexto da Amazônia paraense, onde identificam que este professor «requer diversidades de competências», ou seja, "pessoal, social, cultural, pedagógica, política, ética e estética». Interpretamos, desse modo à formação do educador do campo como elemento imprescindível para a construção da educação do campo na Amazônia paraense enquanto paradigma de construção social. 


\section{Consideraçóes Finais}

O exposto permite evidenciar que a formação docente é condição básica para a conquista do direito de ter acesso à escola e à educaçáo no e do campo. Com base nesse entendimento que o curso de LPEC nasce atrelada a um projeto de sociedade que tem como parâmetro a transformação social. E, portanto, a formação por área significa uma importante estratégia para essa transformação.

Tem-se assim, o desenho de um curso diferente dos moldes consolidado na academia. Daí dizer que essa proposta lançou o desafio de ultrapassar a barreira da oferta dos anos iniciais e ampliar a própria concepção do direito à educação que os movimentos sociais e sindicais do campo vêm construindo na processualidade histórica, demarcada a partir da década de 90. Além disso, a licenciatura configura-se como um importante instrumento na luta por políticas que possibilite a expansão da rede de escolas públicas e, contribua para ampliar a oferta da educaçáo básica no campo e garanta, assim, a implementação das DOEBEC.

A existência da LPEC justifica-se, principalmente pela urgência de açôes afirmativas em vista de reverter à situação educacional existente no campo, sobretudo no que se refere à oferta de educação infantil, anos finais do ensino fundamental e ensino médio. Entende-se que essa licenciatura propóe a inclusão de uma nova organização do trabalho pedagógico das escolas do campo.

A proposição é ajudar a construir a escola do encontro, do debate e, sobretudo, a escola do diálogo, pois, é uma escola de interesses reais, que está pautada em um projeto de sociedade que constantemente tem que disputar espaço no âmbito do Estado capitalista. Daí ser também uma escola de conflitos e diálogos. Caso, contrário a tornaremos em um aparelho novamente hegemônico. Diante disso, que consideramos fundamental desnaturalizar qualquer visão ingênua nesse sentido.

Pode-se afirmar que essa formaçáo em Portel no Marajó, representa para a educação do campo possibilidade de reconhecimento da realidade do campo e dos sujeitos como sujeitos de direitos. Trata-se de uma importante ação afirmativa para a educação do campo na Amazônia paraense e marajoara, visto que é uma possibilidade concreta de se construir e efetivar na prática uma educação capaz de romper com a visão urbanocêntrica, que há muito permeia a educação dos povos que habitam a área rural, e consolidar-se em uma verdadeira e autêntica educaçáo do e no campo da Amazônia Paraense.

Daí refutar que na reescrita dessa história faz-se necessário não só uma formação específica, mas uma epistemologia que possibilite dialogar com 
outras culturas, tanto do campo como da cidade na relação com o mundo. $\mathrm{O}$ ir além da formação específica parece ser uma preocupação da própria política, o que podemos considerar positivo. O Procampo, ao propor formação multidisciplinar por área de conhecimentos corrobora com essa formação no sentido de desenvolver percursos de socialização e sociabilidade na busca de saberes, de valores e da construção de identidades.

\section{REFERÊNCIAS BIBLIOGRÁFICAS}

Antunes-Rocha, Maria Isabel (2009). Licenciatura em Educação do Campo: histórico e projeto político-pedagógico. In Maria Isabel Antunes-Rocha, Aracy Alves Martins (orgs.), Educação do campo: desafios para formação de professores. Belo Horizonte: Autêntica.

Antunes-Rocha, Maria Isabel \& Martins, Ma de Fátima Almeida (2012). Tempo escola e tempo comunidade: territórios educativos na educação do campo. In Maria Isabel Antunes-Rocha, Maria de Fátima Almeida Martins, Aracy Alves Martins (orgs.), Territórios educativos na educaçáo do campo: escola, comunidade e movimentos sociais. Belo Horizonte: Autêntica Editora.

Arroyo, Miguel G. (2011). Currículo, território em disputa. 2. ed. Petrópolis, RJ: Vozes.

Arruda, Élcia E. de \& Brito, Silvia H. A. de (2009). Análise de uma proposta de escola específica para o campo. In Gilberto L. Alves (org.), Educação no campo: recorte no tempo e no espaço (pp. 23-62). Campinas, SP: Autores Associados.

Brasil (2001). MEC. Parecer CNE/CP 9/2001. Diretrizes Curriculares Nacionais para a Formação de Professores da Educação Básica, em nível superior, curso de licenciatura, de graduação plena. Recuperado em 20 de set de 2010 de http://www.mec.gov.br

Brasil (2008). Secretaria de Educação Continuada, Alfabetização e Diversidade Secad. Edital No 2, de 23 de abril de 2008. Chamada Pública para seleção de projetos de Instituiçóes Públicas de Ensino Superior para o Procampo. Recuperado em 20 de set de 2010 de http://portal.mec.gov.br

Caldart, Roseli (2011). Licenciatura em Educação do Campo e projeto formativo: qual o lugar da docência por área? In Mônica C. Molina, Laís M. Sá (orgs.), Licenciaturas em Educação do Campo: registros e reflexóes a partir das experiências piloto. Belo Horizonte: Autêntica.

Cordeiro, Georgina Negrão Kalife (2009). «A relação teoria-prática do curso de formação de professores do campo na UFPA». Tese (Doutorado), 
Universidade Federal do Rio Grande do Norte, Faculdade de Educação. Natal.

Fazenda, Ivani (2008). O que é interdisciplinaridade? São Paulo: Cortez.

Henriques, Ricardo, Marangon, Antonio, Delamora, Michiele \& Chamusca, Adelide (orgs). (2007). Educação do campo: diferenças mudando paradigmas. Brasília, DF: Cadernos Secad/MEC.

IFPA (2011). Projeto Pedagógico Licenciatura em Educação do Campo Área de Concentração: ciências da natureza e matemática. Belém: IFPA (Não publicado).

Jantsch, Ari Paulo \& Bianchetti, Lucídio (2011). Universidade e interdisciplinaridade. In Interdisciplinaridade: para além da filosofia do sujeito (pp. 172182). 9. ed. Petrópolis, RJ: Vozes.

Kuenzer, Acácia Z. (2011). A formação de professores para o ensino médio: velhos problemas, novos desafios. Revista Educação \& Sociedade, 32(116), 667688, jul-set. https://doi.org/10.1590/S0101-73302011000300004

Molina, Mônica C. (2011). Desafios teóricos e práticos na execução das políticas públicas de educação do campo. In Antônio Munarim et al. (orgs.), Educação do Campo: reflexóes e perspectivas. 2. ed. Florianópolis: Insular.

Monteiro, Albêne Lis \& Nunes, Cely (2010). Formação continuada de professores de classes multisseriadas do campo: perspectivas, contradiçóes, recuos e continuidades. In Maria Isabel Antunes-Rocha, Salomão M. Hage, Escola de direito: reinventando a escola multisseriada. Belo Horizonte: Autêntica Editora.

Ribeiro, Marlene (2010). Movimento Camponês, Trabalho e Educação: liberdade, autonomia, emancipação: princípios/fins da formaçâo humana. Sáo Paulo: Expressão Popular.

Santos, Clarice Aparecida dos (2009). «Educação do Campo e políticas públicas no Brasil: a instituição de políticas públicas pelo protagonismo dos movimentos sociais do campo na luta pelo direito à educação». Dissertação (Mestrado). Universidade de Brasília, Faculdade de Educação, 2009. 22 de mai 2011 de http://repositorio.bce.unb.br/bitstream/10482/3939/1/2009_ClariceAparecidadosSantos.pdf 